УДк 94 (470.6)"18"

Д. Ю. Коробейникова

\title{
КОЛОНИЗАЦИОННО-ПЕРЕСЕЛЕНЧЕСКАЯ ДЕФОРМАЦИЯ СЕВЕРОКАВКАЗСКОГО РЕГИОНА В ПРОЦЕССЕ ЕГО АДАПТАЦИИ К ИМПЕРСКОМУ МИРОСОЦИУМУ
}

Статья посвящена характеристике этно-демографической ситуации в северокавказском регионе, сложившейся там перед началом и в ходе активного проникновения в регион Российской империи. Численность местного северокавказского населения постоянно колебалась на протяжении всего присутствия Российской империи в северокавказском регионе. Связано это было с многими факторами, в том числе, с вооружёнными столкновениями, сотрясавшими регион, а также с чередой эпидемий, которые значительно сократили число жителей гор. Попытки российских властей противодействовать распространению эпидемий холеры в крае были мало результативны. С другой стороны, под воздействием России на Северном Кавказе начинают происходить заметные трансформации, которые были связаны с увеличением здесь численности славянского населения и перемещением горских народов с мест их традиционного проживания на новые земли. Появление новых этнических групп переселенцев первоначально не повлекло больших негативных последствий для горских обществ, поскольку новопоселенцы осваивали преимущественно равнинные и степные территории края. Тяготы переселения лишали их сил и средств для осуществления широкой экспансии. Имперские власти также надеялись на социально-культурную трансформацию горских народов, что позволило бы избежать расширения конфликта интересов между сторонами.

Ключевые слова: Северокавказский регион, миросоциум, колонизация, переселенческая политика, адаптация, Российская империя, администрация, этнические общества, конфрликт.

\section{COLONIZING AND RESETTLEMENT DEFORMATION OF THE NORTH CAUCASUS REGION IN THE PROCESS OF ITS ADAPTATION TO THE IMPERIAL MICROSOCIETY}

The article describes the ethnic and demographic situation in the North-Caucasus region, which took place before and during the Russian Empire penetration. The size of the local North-Caucasus population constantly fluctuated throughout the whole period of presentation of the Russian Empire in the North-Caucasus region. It is connected with many facts, including a series of epidemics, which reduced the number of mountaineers. The attempts of Russian authorities to oppose the spread of cholera epidemics in the region failed. On the other hand, some evident transformation took place in the North Caucasus under the Russian influence, namely the increase of the Slavonic population and resettlement of highlanders

K началу XIX столетия этнодемографическая картина на Северном Кавказе выглядела уже сложившейся и относительно устойчивой. За каждым народом закрепилась определённая территория и, хотя границы, время от вре- from their traditional areas to new lands. Originally new ethnic resettlement groups entailed no significant negative consequences for mountain societies, since the new settlers chiefly developed flat and steppe areas of the region. The difficulties of the migration deprived them of the power and means to expanse widely. The imperial authorities also hoped to transform mountain peoples socially and in cultural fields, so that it could provide an opportunity to localize the conflict of interests between the parties.

Key words: The North-Caucasus region, microsociety, colonization, resettlement politics, adaptation, the Russian Empire, authority, ethnic societies, conflict.

мени, подвергались незначительной корректировке, масштабных перемещений населения не происходило.

Северокавказский мир (миросоциум) на тот момент представлял собой достаточно пё- 
стрый конгломерат, состоявший из различных сообществ, придерживавшихся определённого порядка как во внутренних, так и во внешних взаимодействиях, и в основании которого лежала выработанная долговременным опытом система сдержек и противовесов.

Миросоциум представляет собой тесную связь и взаимную обусловленность географического и социокультурного пространства. Особенности каждого региона влияют на становление и фрунционирование «общественных институтов, связанных тесными узами с фризико-географическими структурами региона, которые предопределяли формы существующего там общественного быта и хозяйственной деятельности» [9, с. 90].

При кажущейся стабильности такое мироустройство было весьма уязвимо для внутри- и внешнеполитического воздействия, и усиливавшийся российский фрактор неминуемо должен был повлиять на сложившееся положение вещей.

На территории Северо-Западного Кавказа проживали многочисленные черкесские племена. Процесс их этнической консолидации был ещё далёк от завершения, а потому они делились на шапсугов, натухайцев, убыхов, абадзехов, жанеевцев и т.д. При внешней схожести, они имели свои особенности, в большей степени связанные с мировоззренческой обособленностью, что характерно для народов, до конца не изживших традиции архаики.

В силу объективных обстоятельств малочисленные этнические группы черкесов поглощались более крупными. Этот процесс аккультурации имел относительно мирный характер и не был связан с военно-политическими катаклизмами, в которые оказался втянут регион в первой половине XIX столетия. Живущие в горных труднодоступных районах этнические сообщества в меньшей степени были подвержены инокультурному воздействию. В этом отношении их равнинные сородичи легче шли на контакт и выстраивали межкультурный диалог со своими соседями. Это заметно по бжедухам, темиргоевцам либо по абазинам-тапантинцам (их родичи-горцы назывались «шакаруа»), кубанским ногайцам. Именно они станут своеобразным связующим звеном между русскими поселенцами и своими горскими соотечественниками. Они будут носителями пограничного, весьма непростого сознания, будучи вынужденными лавировать между двумя «центрами силы».

Восточнее (в горных районах Приэльбрусья) проживали тюркоязычные карачаевцы, а в ущельях Баксана, Чегема, Черека, Урвани жили родственные им балкарцы. Замкнутые в горных теснинах, они зависели от контролирующих равнины кабардинцев, которые стремились максимально использовать своё положение и распространить собственную власть над этими народами. Всё это предопределило возникновение латентной конфрликтной ситуации, разрешить которую без ущерба для каждой из сторон было крайне трудно.

В центральной части Главного Кавказского хребта проживали осетинские общества. Расположившись в ущельях, они испытывали серьёзные проблемы, связанные с невозможностью обеспечить себя необходимым количеством продовольствия, несли существенные потери при возникновении эпидемий и т.п. Выходом из этой непростой ситуации было освоение Владикавказской равнины, но в условиях военно-политической нестабильности этот процесс был затруднён.

Аналогичные сложности испытывали и соседи осетин - ингуши. Для них появление российских укреплений стало историческим шансом, дававшим возможность вырваться из «горного мешка».

Восточнее разместились чеченские этнические общности. Увеличив свою численность, они начинали теснить соседей, стремясь закрепить за собой новые территории. По словам Умалата Лаудаева, «с этих пор чеченцы начинают уже более выясняться в глазах соседних народов; до того живя в горах и отражая хищнические нападения соседей, они теперь сами выходят из домов своих и пускаются за добычей в чужие земли. Они сами тревожат рубежи, и потомство в песнях передаёт как их удачные битвы, так и поражения. <..> Наконец, в это же время они принимают ислам и делаются религиозными врагами как русских, так и язычествующих соседей своих и собратьев» [10, с. 20]. Неудивительно, что российской администрации было трудно выстраивать взаимоприемлемый диалог с этими племенами.

На Северо-Восточном Кавказе проживали народы, принадлежавшие к самым различным этническим сообществам. Они отличались не только языковой спецификой, но и социально-политической организацией, степенью открытости для восприятия тех новаций, которые несла им империя.

Если к этой пёстрой картине добавить ещё и дисперсное расселение выходцев с территории Закавказья, казачьи станицы и русские (шире - славянские) крестьянские поселения, становится очевидным, что специфика 
северокавказского миросоциума делала его непростым для взаимодействия феноменом. Выработать некую универсальную формулу взаимоотношений его с российским государством было трудноразрешимой задачей.

Следует помнить также о том, что количество местного северокавказского населения постоянно колебалось. Связано это было с вооружёнными столкновениями, сотрясавшими регион, а самое главное - с чередой эпидемий, которые значительно сократили число автохтонов. Достаточно вспомнить высказывание А. П. Ермолова о Кабарде: «Моровая язва была союзницею нашею против кабардинцев; ибо, уничтожив совершенно всё население Малой Кабарды и производя опустошение в Большой, до того их ослабила, что они не могли уже как прежде собираться в больших силах...» [4, с. 283].

Попытки российских властей снизить угрозу эпидемии были мало результативны. Это признавали и сами царские генералы. Вновь обратимся к авторитету А. П. Ермолова: «Впрочем от заразы в здешней стране едва ли возможно предохраниться, сколько в таковых случаях спасительна предосторожность, но можно ли таковой ожидать от простолюдина, иначе от мусульман, верящих предопределению» [4, с. 303].

Таким образом, катастрофические демографические потери горских обществ были связаны со многими факторами, повлиять на которые оказалось весьма сложно в силу самых разных, в том числе субъективно-ментальных причин.

В силу того, что весьма трудно подробно раскрыть все аспекты влияния имперского миросоциума на северокавказскую этнополитическую картину, для нас является важным показать общую тенденцию демографических изменений в регионе и проиллюстрировать этот процесс на примере ярких исторических фактов-маркеров, имевших место в процессе встраивания местных сообществ в державное пространство России.

Под воздействием России на Северном Кавказе начинают происходить заметные трансформации, которые были связаны с увеличением здесь численности славянского населения и перемещением горских народов с мест их традиционного проживания на новые земли. Эти процессы с разной долей интенсивности происходили как в первой половине XIX столетия, так и продолжались во второй. Менялись лишь побудительные мотивы, которые толкали власти и население на такие шаги. Если первоначально мы видим весомость значения военно-политической необходимости, то в дальнейшем на первое место выходит фрактор экономической целесообразности [2, с. 282-285].

B начале XIX столетия на Кавказской линии проживали преимущественно казаки, которые могли не только заниматься сельским хозяйством, но и принимали активное участие в охране и обороне границы. Их численности явно не хватало для выполнения этой важной миссии, а потому правительство принимает решение переселить сюда дополнительный контингент. Инициатором этого шага явился генерал А. П. Ермолов, который ратовал за превращение Кавказа в казачий край. Сюда с 1825 по 1827 гг. прибыло 11 новых станиц, размещённых преимущественно в центральных районах края. Ещё через три года к ним добавилось 15 новых. Это приводило к формированию новой этнополитической реальности на Северном Кавказе, хотя и не затрагивало интересы большинства горских народов региона.

Уплотнившееся казачье прикрытие границы позволило приступить к крестьянскому освоению южного пограничья. В сентябре 1830 г. принимается положение, согласно которому казённые крестьяне, имевшие проблемы с получением необходимого земельного надела, могли перебраться на Кавказ и здесь обзавестись собственным хозяйством. Они достаточно быстро адаптировались в новых условиях и вскоре были переведены в разряд казачьих станиц. Происходил процесс «окавказивания» русского крестьянства, которое постепенно воспринимало новые для себя ментальные ценности и приоритеты.

Процесс славянского освоения региона шёл по нарастающей. Возведение новых пограничных линий по рекам Сунжа, Лаба, Зеленчук и т.д. привело к тому, что здесь казачье население к середине века оценивалось в 241794 человека [5, с. 58].

Усиливается внимание властей к славянской колонизации Северо-Западного Кавказа. Исторически сложилось так, что долгое время интересы Российского государства были сосредоточены на другой, восточной части края. Между тем с точки зрения геополитической необходимости Азовско-Черноморский регион, пожалуй, доминировал в обеспечении безопасности южных рубежей страны. Это явственно покажет Восточная война, когда отряды западноевропейских противников России, опираясь на поддержку «немирных» горцев, попытаются организовать отсюда прорыв вглубь территории империи. Но и до этих трагических событий значение данной территории в Петербурге оценивали достаточно трезво. Поэтому, сюда 
старались поселить людей, в лояльности которых власти не сомневались.

Помимо казаков, на территории правобережья, а затем и левобережья Кубани стали появляться и выходцы из крестьянской среды, которых в дальнейшем будут называть иногородними. Их интерес к краю был настолько велик, что царская администрация даже принимала запретительные меры, пытаясь ограничить неконтролируемый приток самовольных колонистов. Но потребность в новых рабочих руках была столь велика, что местная власть зачастую покрывала таких новосёлов, хотя и стремилась не допустить предоставления им таких же прав, как старожильческому казачьему населению.

Весьма информативным видится в этой связи обращение императора Александра I к генералу А. П. Ермолову, который должен был организовать переселение и осуществлять контроль за малороссийскими казаками, размещавшимися в Черномории. В частности, он отмечал, что «при утверждении Мною в прошлом 1820 году известного вам положения о переселении на земли Черноморского Войска 25000 малороссийских казаков, обращено было внимание на открывшееся из донесений ген.-м. Киселёва обстоятельство, что некоторые из чиновников Войска Черноморского учредили из земель оного частные владения и поселили на оных крестьян. Предусматривая, что из сего произойти могут стеснения казаков в землях их и другие злоупотребления, предположено сие несообразное с существованием Войска Черноморского и по единому послаблению допущенное установление уничтожить; крестьян же, на землях войсковых поселённых, коих чиновники, ими владеющие, не пожелают перевести на земли или в имения, в других губерниях им принадлежащие, обратить в казаки, сделав им надлежащее за них удовлетворение» [1, с. 657].

Обратим внимание на тот фракт, что в происходившие процессы колонизации был вынужден вмешаться лично император. Несмотря на попытку государства регулировать данный процесс, он происходил достаточно хаотично, и ждать скорых позитивных результатов по адаптации новопоселенцев на Кавказе не приходилось.

Правительство и само отдавало себе отчёт, что найти желающих осваивать новые территории - занятие хлопотное, и легче было компенсировать потери бывшему владельцу беглых крестьян. С этой целью ему выдавались рекрутские квитанции, и таким образом ущерб от поте- ри крепостного минимизировался. В императорском указе от 15 августа 1801 г. говорилось, что таких беглецов «...повелено оставить на месте, и снабдив их землёю, считать принадлежащими тому, чьи они были по четвертной ревизии, повелеваем зачтя помещикам их за рекрут по узаконению, причислить в казённое ведомство и обложить податями на равне с прочими государственными поселянами» [11, с. 748].

Отметим, что далеко не все оказавшиеся на Кавказе переселенцы были довольны своим новым положением. Было немало тех, кто готов был выехать отсюда и искал малейшую возможность, чтобы добиться этого. Сохранился весьма любопытный документ, датируемый 1838 г. в котором говорилось: «Начальник ставропольской жандармской команды штабс-капитан Полесский-Щепило обнаружил, что отставной подпоручик Ремизов составил фальшивый высочайший указ, дозволяющий переселенцам возвращаться из Кавказской области в Россию, по коему многие однодворцы уже подали прошения на высочайшее имя о их возвращении с Кавказа, что произвело в том крае некоторое беспокойство, и только открытием Полесского-Щепило в подлоге указа прекращено» [7, с. 26]. Сложно сказать, чего добивался отставной подпоручик, когда затевал подобную аферу, и какой был его личный интерес в этой мистификации. Для нас важно понять, какие настроения царили среди новосёлов, которые с трудом адаптировались на новом месте и долгое время не считали Кавказ своей новой малой родиной.

Вместе с крестьянами на Северный Кавказ пришли новые социальные реалии и проблемы. Они первое время мало касались горской части северокавказского миросоциума, который столкнётся с похожими трудностями после завершения вооружённого противостояния в крае и активного распространения здесь капиталистических порядков.

В первые десятилетия XIX в. государственные крестьяне стали той социокультурной средой, которая должна была продемонстрировать все преимущества имперских порядков, которые несла с собой Россия. Для горцев долгое время империя ассоциировалась с военной мощью, а экономическое освоение новых земель явно задерживалось. На то были свои объективные причины, что, впрочем, не снимало ответственности с царской администрации, которая должна была предпринимать шаги по развитию в крае условий для его экономического процветания. 
Государственные крестьяне весьма тяжело встраивались в непривычные для себя реалии. Уровень их достатка был невелик, а переезд и обзаведение хозяйством на новом месте зачастую оказывались настолько разорительными, что они не только не могли продемонстрировать хозяйственные успехи, но сами оказывались на грани физического выживания.

Как вспоминал А. П. Ермолов, «...нашёл я переселяемые из Малороссии семейства в ужаснейшей бедности. Войско без всяких средств вспомоществовать им по истощению своих доходов. В одно время выслано из Малороссии вдвое большее число, нежели распоряжено было правительством. На прежних жилищах своих продавали они имущество за бесценок, ограблены были земской полиции чиновниками, отправлены в путь в самое позднее осеннее время, и многие, весьма лишившись по дороге скота своего, без средств идти далее, остались зимовать по разным губерниям, выпрашивая для существования милостыню» [4, с. 373-374]. Власти вынуждены были обратиться к старожилам с призывом поддержать новопоселенцев, чтобы те не умерли от голода [3, с. 406].

И в дальнейшем избегать проблем с размещением вновь прибывших поселян не удавалось. Среди прочего сказывался субъективный фактор, когда, например, топографы, которым давалось распоряжение подыскать для новых поселян удобное место жительства, ошибались, и это дорого стоило для колонистов [6, с. 190].

Рискнём предположить, что их пример не только не способствовал формированию привлекательного имиджа России, но наоборот показывал горскому миросоциму его преимущество перед ней. Положительный эфффект должен был проявить себя лишь после длительного этапа адаптации русских колонистов на новом месте, а потому в диалоге с горскими обществами в качестве аргумента нередко использовали силу армии.

Не выказывали большого желания переселять своих крепостных на Северный Кавказ и помещики. Такой рискованный шаг был под силу лишь крупным владельцам, но они, как правило, имели необходимые земельные наделы в центральных губерниях страны. Щедрые раздачи новых участков ситуацию не изменили, а потому даже к середине XIX столетия во всём Предкавказье было примерно 2 \% крепостных крестьян [5, с. 60].

Ещё одним колонизационным ресурсом империи были иностранные поселенцы [8, с. 206-208]. В них видели носителей передовых хозяйственных традиций, которые должны были стать примером как для русских поселян, так и для горских жителей Кавказа. С этой целью таким колонистам давали самые широкие права и значительную автономию в организации внутренней жизни. Нередко они сочетали свою хозяйственную жизнь с миссионерской деятельностью, как это, к примеру, сделали поселенцы Шотландской колонии в Пятигорском округе [12, с. 243-253].

Однако иностранные колонисты (речь идёт в первую очередь о немцах), жили достаточно замкнуто и не спешили передавать свой опыт другим народам региона. Кроме того, воспользоваться их примером было затруднительно, т.к. для этого нужно было иметь и те льготы, которыми наделило их российское правительство. Численность таких переселенцев была несопоставима с русской казачьей и крестьянской колонизацией, а потому и знакомство с ними основного этнического массива северокавказского миросоциума было затруднено [6, с. 208].

Таким образом, появление новых крупных этнических массивов долгое время не приводило к кардинальным деформациям уже сложившегося горского миросоциума. Русские поселения осваивали преимущественно равнинную, степную часть края. Однако этот процесс проходил с серьёзными людскими и материальными издержками для самих новопоселенцев, не оставлял им сил и средств на расширение экспансии в другие районы края. Долгое время такая задача и не ставилась властями. Сохранялась надежда, что автохтоны под воздействием культурных и экономических факторов изменят свой образ жизни, и удастся избежать дальнейшего конфликта между имперским и горским миросоциумами. Дальнейшие события показали, что такой сценарий развития событий был неоправданно оптимистичен. Немалая часть местных сообществ оказалась недоговороспособной и предпочла погибнуть в борьбе против нового миропорядка или перебраться на территорию Турции.

\section{Источники и литература}

1. Акты собранные Кавказскою археографическою комиссиею. Т.VI. Ч.ІІ.Тифлис: Типография Главного Управления Наместника Кавказского, 1875. 1019 с.

2. Гранкин Ю. Ю. Колонизационная политика Российской администрации на Северо-Западном Кавказе в конце 40-50-е гг. XIX в.: задачи и реализация // Вестник Пятигорского государственного лингвистического университета. 2015. №2. C. 282-285. 
3. Записки Алексея Петровича Ермолова с приложениями / издание Н. П. Ермолова. Ч.ІІ. 1816-1827. М.: Катков и $\mathrm{K}^{\circ}, 1868.442 \mathrm{c}$

4. Записки А. П. Ермолова. 1798-1826 гг. / сост., подгот. текста, вступ. ст., коммент. В. А. Федорова. М.: Высш. шк., 1991. 463 c.

5. История народов Северного Кавказа (конец XVIII в. - 1917 г.) / отв. ред. А. Л. Нарочницкий. М.: Наука, 1988. 659 с.

6. Клычников Ю. Ю. Российская политика на Северном Кавказе (1827-1840 гг.). Пятигорск: изд-во ПГЛУ, 2002. 494 с.

7. Крестьянское движение 1827-1869 годов / подготовила к печати Е. А. Мороховец. М.: Государственное социально-экономической издательство, 1931. 164 с.

8. Лазарян С. С. Экономическая, социальная и этноконфессиональная политика князя М.С. Воронцова в Кавказском крае. 1845-1854 гг. Пятигорск: ПГЛУ, 2014. 398 с.

9. Лазарян С. С. Роль ландшафртов в истории взаимодействия России с горскими обществами в период Кавказской войны 1817-1864 гг. // Историческая память и культурные символы национальной идентичности. Материалы международной научной конференции (Пятигорск, 18-20 октября 2017 г.). Ставрополь-Пятигорск: ПГУ, 2017. С. 90-92.

10. Лаудаев У. Чеченское племя (с примечаниями) // Сборник сведений о кавказских горцах. T.VI. Тифлис, 1872. C. 1-62.

11. Полное собрание законов Российской империи, с 1649 года. Том XXVI. 1800-1801. СПб., 1830. №19979. 883 с.

12. Чекменёв С. А. Иностранные поселения на Ставрополье в конце XVIII и в первой половине XIX в. // Материалы по изучению Ставропольского края. Ставрополь: Книжное издательство, 1971. С. 243-253.

\section{References}

1. Akty sobrannye Kavkazskoyu arheograficheskoyu komissieyu (Acts, collected by the Caucasian archaeological committee). Vol.VI. Part. II. Tiflis, 1875. 950 p. (In Russian).

2. Grankin Yu. Yu. Kolonizacionnaya politika Rossijskoj administracii na Severo-Zapadnom Kavkaze v konce 40-50-e gg. XIX v.: zadachi i realizaciya (The colonizing politics of the Russian authorities in the North-Western Caucasus in the end of 40-50-s of the XIX c.) // Vestnik Pyatigorskogo gosudarstvennogo lingvisticheskogo universiteta. 2015. No.2. P. 282-285. (In Russian).

3. Zapiski Alekseya Petrovicha Ermolova s prilozheniyami (The notes of A.P. Ermolov with the appendices). Part. II. 18161827. Moscow, 1868. 442 p. (in Russian).

4. Zapiski A. P. Ermolova. 1798-1826 gg. (The notes of A. P. Ermolov. 1798-1826). Moscow: Hight school publ., 1991. 463 p. (In Russian).

5. Istoriya narodov Severnogo Kavkaza (konec XVIII v. - 1917 g.) (The history of the North-Caucasian peoples. The end of the XVIII c. - 1917) / ed. by A.L. Narochnickij. Moscow: Nauka, 1988. 659 p. (In Russian).

6. Klychnikov Yu. Yu. Rossijskaya politika na Severnom Kavkaze (1827-1840 gg.) (The Russian politics in the North Caucasus (1827-1840 y). Pyatigorsk: PSLU publ., 2002. 494 p. (In Russian).

7. Krest'yanskoe dvizhenie 1827-1869 godov (The peasants rising of 1827-1869). Moscow: Gosudarstvennoe social'noehkonomicheskoj izdatel'stvo, 1931. 164 p. (In Russian).

8. Lazaryan S. S. EHkonomicheskaya, social'naya i ehtnokonfessional'naya politika knyazya M. S. Voroncova $v$ Kavkazskom krae. 1845-1854 gg. (The economic, social, ethnic and confessional politics of prince M. S. Vorontsov in the Caucasus region. 1845-1854). Pyatigorsk: PSLU publ., 2014. 398 p. (In Russian).

9. Lazaryan S. S. Rol landshaftov v istorii vzaimodejstviya Rossii s gorskimi obschestvami v period Kavkazskoj vojny 1817$1864 \mathrm{gg}$. (The role of landscapes in the history of the interaction between Russia and mountain societies in the period of the Caucasian war 1817-1864) // Istoricheskaya pamyat i kulturnye simvoly nacionalnoj identichnosti. Materialy mezhdunarodnoj nauchnoj konferencii (Pyatigorsk, 18-20 oktyabrya 2017 g.). Stavropol-Pyatigorsk: PSU publ., 2017. P.90 - 92.

10. Laudaev U. CHechenskoe plemya (s primechaniyami) (The Chechen tribe (with notes) // Sbornik svedenij o kavkazskih gorcah. Vol.VI. Tiflis, 1872. P. 1-62. (in Russian).

11. Polnoe sobranie zakonov Rossijskoj imperii, s 1649 goda (The complete works of the Russian Empire laws of 1649). Vol. XXVI. No.19979. 1800-1801. St.Petersburg, 1830. 883 p. (In Russian).

12. Chekmenyov S. A. Inostrannye poseleniya na Stavropol'e v konce XVIII i v pervoj polovine XIX v. (Foreign settlements in the Stavropol region in the end of the XVIII and first half of the XIX c.) // Materialy po izucheniyu Stavropol'skogo kraya. Stavropol', 1971. P. 243-253. (In Russian). 